\title{
Announcement of the Fulker Award for a Paper published in Behavior Genetics, Volume 40, 2010
}

The Fulker Award was established by the Behavior Genetics Association in memory of David Fulker, a past President of the Association and Executive Editor of the journal, who died in 1998 (Hewitt 1998). The award is for 'a particularly meritorious paper' published in the journal during the preceding year. The annual prize is $\$ 1000$ 'and a nice bottle of wine' (given only when the recipient is present at the Association's annual meeting).

Volume 40 was another very impressive volume comprising 73 high quality peer reviewed papers. To select the paper for the Fulker award, I solicit nominations from the journal's Associate Editors and follow their advice closely.

Among the nominations from Associate Editors were both animal and human studies. One paper by Velez et al. (2010) identified a robust difference in aggressive behavior between BALB/cJ and BALB/cByJ substrains, which could be the result of Copy Number Variants that they identified differentiating the two substrains. Another by Eaves et al. (2010) showed how the longitudinal study of twins and their parents makes it possible to demonstrate there is a direct causal effect of childhood adversity on child conduct disorder over and above any indirect genetic correlation. A third paper, this year's winner, was a rigorous methodological inquiry into the utility of extended twin family designs. In this study, Matt Keller, Sarah Medland, and Laramie Duncan, used precisely specified but comprehensive algebraic models incorporating a wide range of potential parameters, sophisticated computer programs, and extensive simulations, to explore the bias, precision, and accuracy of estimates from the classical twin design and three increasingly complex extended twin family designs (Keller et al. 2010). They show that the classical twin design "does a decent job of estimating broad sense heritability, but $[\ldots]$ estimates of shared environmental effects and the relative importance of additive versus non-additive genetic variance can be biased, sometimes wildly so. Increasingly complex extended twin family designs, on the other hand, are more accurate and less sensitive to assumptions than simpler models." These conclusions accord with our general sense of how things work, but this study provides a definitive and rigorous exploration of these issues that is guiding the design and interpretation of twin and family studies in behavior genetics.

Congratulations to Matt Keller, Sarah Medland, and Laramie Duncan on winning the 2010 Fulker Award.

John K. Hewitt

Editor-in-Chief

\section{References}

Eaves LJ, Prom EC, Silberg JL (2010) The mediating effect of parental neglect on adolescent and young adult anti-sociality: a longitudinal study of twins and their parents. Behav Genet 40(4):425-437

Hewitt JK (1998) David William Fulker (1937-1998). Behav Genet. 28:239-241

Keller MC, Medland SE, Duncan LE (2010) Are extended twin family designs worth the trouble? A comparison of the bias, precision, and accuracy of parameters estimated in four twin family models. Behav Genet 40(3):377-393

Velez L, Sokoloff G, Miczek KA, Palmer AA, Dulawa SC (2010) Differences in aggressive behavior and DNA copy number variants between $\mathrm{BALB} / \mathrm{cJ}$ and $\mathrm{BALB} / \mathrm{cByJ}$ substrains. Behav Genet 40(2):201-210 